\title{
RECOMENDAÇÕES PARA TRADUÇÃO E CRIAÇÃO DE IMAGENS TÁTEIS IMPRESSAS EM 3D
}

\section{RECOMMENDATIONS FOR THE TRANSLATION AND CREATION OF 3D PRINTED TACTILE IMAGES}

\author{
Emilia Christie Picelli Sanches ${ }^{1}$, Mestranda \\ Claudia Mara Scudelari de $\mathrm{Macedo}^{2}$, Dra. \\ Juliana Bueno ${ }^{3}$, Dra. \\ (1) Universidade Federal do Paraná \\ e-mail: emilia.ecps@gmail.com \\ (2) Universidade Federal do Paraná, Pontifícia Universidade Católica - PR \\ e-mail: claudia.scudelari@gmail.com \\ (3) Universidade Federal do Paraná \\ e-mail: oieusouaju@gmail.com
}

Acessibilidade, imagens táteis, cegueira

Este artigo visa coletar e discutir as recomendações encontradas na literatura sobre planejamento e criação de imagens táteis para pessoas cegas, com foco na utilização da impressão 3D e aplicação em contextos educacionais. Para isso, busca compreender a cegueira, seus meios de percepção do conteúdo visual, e explora a literatura da cartografia tátil, da produção de imagens táteis e das aplicações da impressão 3D na produção de imagens táteis. Como resultado, reúne recomendações da literatura sobre tradução e planejamento de imagens táteis.

Accessibility, tactile images, blindness

This article aims to gather and discuss recommendations found in the literature about planning and creation of tactile images for blind people, focusing on the $3 D$ printing use and educational contexts applications. To achieve that, it is investigated concepts of blindness, ways of perception of visual content, and it explores the literature of tactile cartography, of the tactile images production and the $3 D$ printing applications on the production of tactile images. As the result, the article gathers the literature recommendations about translation and planning of tactile images. 


\section{$16^{\circ}$ \\ ERGODESIGN USIHC CINAHPA}

\section{Introdução}

Estima-se que 1 entre 7 pessoas no mundo possui algum tipo de deficiência [UN, 2016]. No Brasil, esse número ocupa $23,9 \%$ da população, com o total de 45.606.048 habitantes, segundo o censo demográfico de 2010 do Instituto Brasileiro de Geografia e Estatística [IBGE, 2010]. Ainda segundo esse censo, constata-se que a deficiência visual é a que mais atinge os brasileiros, totalizando $77,4 \%$ das pessoas que declararam possuir ao menos uma das deficiências investigadas (deficiência: motora, visual, auditiva e intelectual). Esses números expressivos refletem na necessidade de inclusão e acessibilidade, de fato, dessas pessoas em áreas distintas, que vão desde o acesso à informação até a locomoção e acessibilidade às edificações.

Para promover a acessibilidade de pessoas com deficiência visual, e em especial as pessoas cegas, é necessário compreender como elas processam a informação e entender suas habilidades e capacidades cognitivas. Na educação, por exemplo, entender como os cegos processam a informação em especial, a visual - é imprescindível para a tradução e adaptação de materiais didáticos, promovendo o acesso igualitário tanto para pessoas cegas quanto para videntes. $\mathrm{E}$, no caso, como os cegos não podem utilizar o visual como forma de percepção da informação, os sentidos auditivos e táteis são exaltados e estimulados a receber o conteúdo visual adaptado [SACKS, 2010].

Nesse sentido, imagens táteis formam um recurso importante para a compreensão de informações visuais. Há, porém, que se discutir como traduzir e adaptar imagens visuais para imagens táteis de forma que cegos as compreendam. Sendo assim, é sobre esse pensamento que a pesquisa se pautou, buscando na literatura as recomendações de autores sobre o planejamento e construção de imagens táteis.

Em adição, como foco específico da pesquisa bibliográfica, optou-se pela procura de recomendações sobre a utilização da tecnologia de impressão 3D, pois diversos autores apontam como $16^{\circ}$ Ergodesign - Congresso Internacional de Ergonomia e Usabilidade de Interfaces Humano Tecnológica: Produto, Informações Ambientes Construídos e Transporte

$16^{\circ}$ USIHC - Congresso Internacional de Ergonomia e Usabilidade de Interfaces Humano Computador

CINAHPA | 2017 - Congresso Internacional de Ambientes Hipermídia para Aprendizagem.

a utilização de impressos 3D é compatível com a ideia de acessibilidade e educação de pessoas com deficiência visual [GRUENWALD, 2014; ORTÍ et al., 2014; SOBRAL; CAVALCANTI; EVERLING, 2015; FLORES et al., 2015; CHICCA JUNIOR; CASTILLO; COUTINHO, 2015].

Portanto, este artigo parte de uma revisão bibliográfica sobre recomendações de criação de imagens táteis, incluindo tanto recomendações gerais quanto recomendações sobre imagens táteis impressas em 3D, por se entender que são informações complementares.

Então, o presente artigo inicia-se com um breve contexto sobre cegueira e Tecnologia Assistiva, para posteriormente apresentar a percepção tátil e as imagens táteis. Em seguida, são expostas as recomendações gerais da literatura sobre imagens táteis e o uso da impressora 3D na produção destas imagens. Por fim, se segue um quadro comparativo e uma discussão acerca das recomendações encontradas sobre a criação de imagens táteis impressas em 3D.

\section{Cegueira e Tecnologia Assistiva}

O termo cegueira é definido como "a perda total da visão ou pouquíssima capacidade de enxergar" [FUNDAÇÃO DORINA NOWILL, 2017], fazendo com que a percepção de mundo das pessoas cegas seja ocasionada pelos sentidos auditivos, cinestésicos e táteis [AMIRALIAN, 2009]. Em um âmbito pedagógico, a pessoa cega necessita utilizar o sistema Braille para leitura e escrita, além de outros recursos assistivos [QUEVEDO; ULBRICHT, 2011], como audiodescrição e imagens táteis. Amiralian [1997] ainda difere a cegueira adquirida e a congênita. A sasber, pessoas que nasceram cegas ou perderam a visão até os 5 anos de idade são consideradas cegas congênitas, ao passo que a cegueira adquirida acontece após esta idade.

Assim, como o campo perceptivo do cego é transferido para outro centro que não o visual, seu córtex visual pode ser empregado para processamento de sons e estímulos táteis, estabelecendo imagens mentais de tudo o que o
Realização:

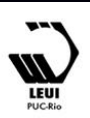




\section{$16^{\circ}$ \\ ERGODESIGN USIHC CINAHPA}

cerca, inclusive informações visuais, com ou sem a ajuda de Tecnologia Assistiva [KURZE, 1996; SACKS, 2010].

A Tecnologia Assistiva visa a autonomia, independência, inclusão e qualidade de vida de pessoas com deficiência [BRASIL, 2009]. Por isso, contribui significativamente para a percepção imagética de pessoas cegas. Dentre os recursos assistivos que colaboram com a diminuição de problemas e auxiliam nas interações com conteúdos visuais, é possível citar a impressão do sistema Braille, a audiodescrição, os leitores de tela e as imagens táteis [MACEDO, 2010; QUEVEDO, ULBRICHT, 2010]. A audiodescrição e os leitores de tela utilizam o sentido auditivo, enquanto o Braille e as imagens táteis, o sentido tátil.

\section{Imagens táteis}

A utilização do tato pelas pessoas cegas é, de acordo com Duarte [2011], muito frequente para o reconhecimento de objetos. Estes objetos englobam desde pessoas e objetos do cotidiano até imagens táteis em contextos de mobilidade ou educacionais. Porém, o tato, ao contrário da visão, é sequencial-temporal, ou seja, é realizado por partes, no tempo em que as mãos percorrem toda a área do objeto [DUARTE, 2011]. A autora ainda sugere que a percepção tátil seja estimulada desde criança, pois, como complementa Kastrup [2007], embora o tato pode sobrecarregar a atenção e a memória do cego, esse processo de aprendizagem deixa a percepção rápida e automática, diminuindo a carga cognitiva empregada.

As imagens táteis são traduções e adaptações de imagens visuais, com o objetivo de permitir que um usuário cego tenha acesso ao mesmo conteúdo que uma pessoa vidente. São utilizadas com mais frequência em contextos educacionais, como: ilustrações em livros de histórias, imagens em livros pedagógicos e didáticos, tradução tátil de obras de arte pictóricas em museus ou livros, ou em imagens de disciplinas como biologia, história e geografia [LOCH, 2008; VALENTE, 2009]. Além disso, essas imagens táteis podem ser aplicadas tanto para acessibilidade de imagens $16^{\circ}$ Ergodesign - Congresso Internacional de Ergonomia e Usabilidade de Interfaces Humano Tecnológica: Produto, Informações Ambientes Construídos e Transporte

$16^{\circ}$ USIHC - Congresso Internacional de Ergonomia e Usabilidade de Interfaces Humano Computador

CINAHPA | 2017 - Congresso Internacional de Ambientes Hipermídia para Aprendizagem. encontradas em meios físicos (livros, por exemplo) ou digitais (objetos de aprendizagem, etc.).

Os processos mais comuns para a produção das imagens táteis são o artesanal, a termoformagem (Figura 1) e a impressão em relevo (Figura 2).

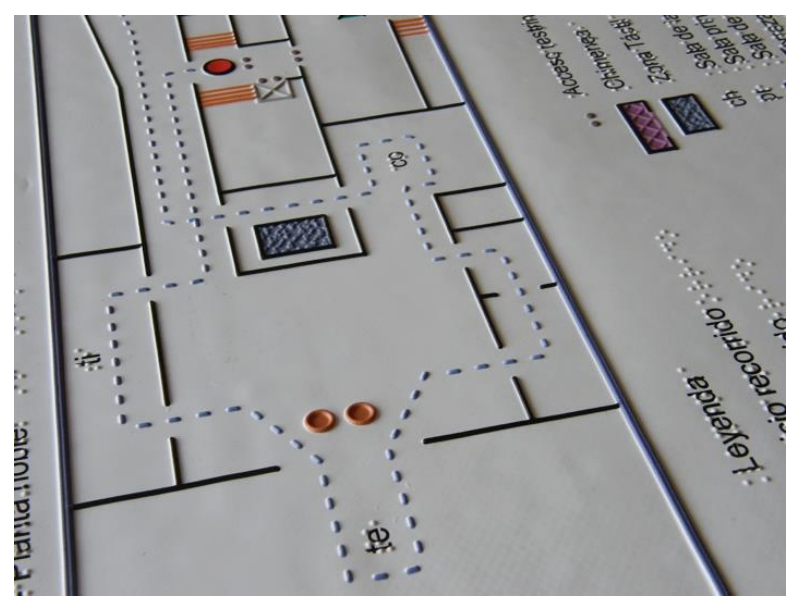

Figura 1 - Termoformagem. Fonte: Ortí et al. [2014].

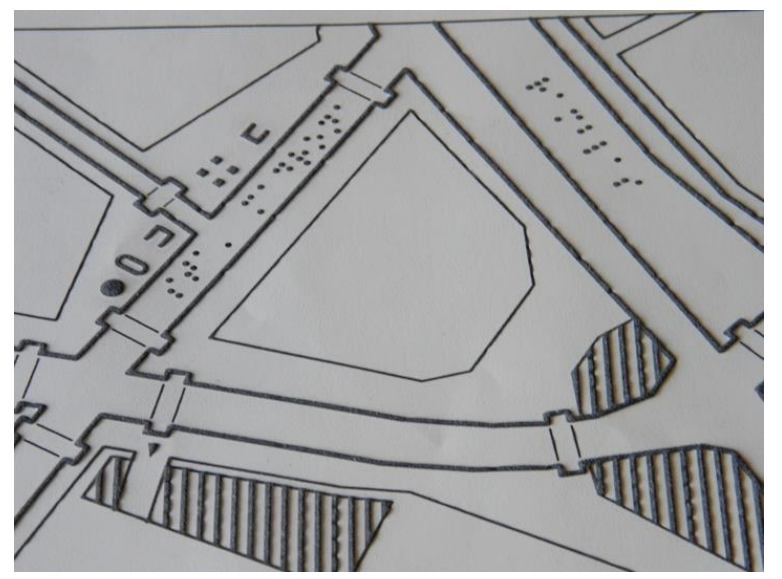

Figura 2 - Impressão em relevo. Fonte: Gual; Puyuelo; Lloveras [2014].

Outro processo emergente neste ramo é o da impressão 3D (Figura 3).
Realização:
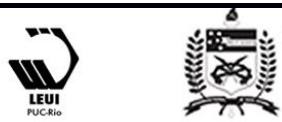


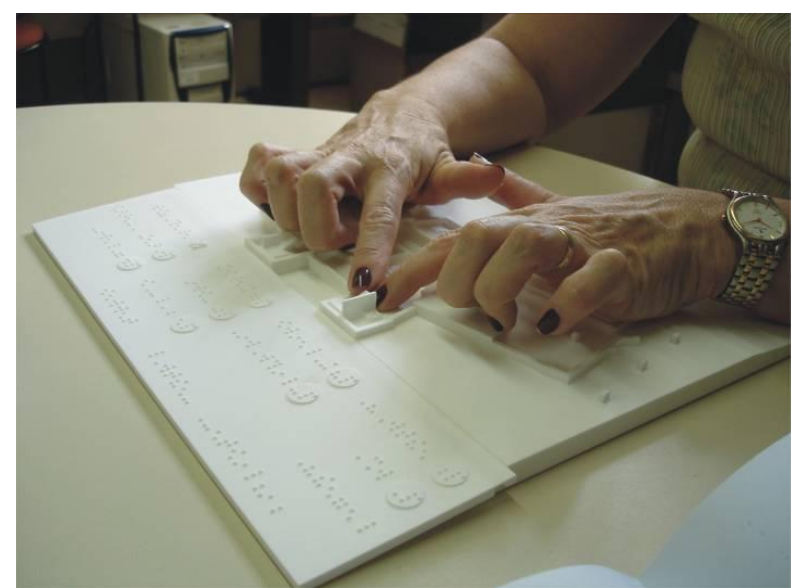

Figura 3 - Impressão 3D. Fonte: Celani; Milan [2007].

Tendo em mente a compreensão da percepção tátil dos cegos e a aplicação das imagens táteis para captação de informações, é necessário entender quando utilizar este recurso, ou mesmo como traduzir uma imagem visual em imagem tátil. Nessa questão, Gruenwald [2014] afirma que imagens simples podem ser satisfatoriamente traduzidas por áudio, mas imagens complexas demandam o tátil. A complexidade de uma imagem visual pode ter relação com conceitos que envolvem localização espacial, como mapas, ou utilização de temas visuais, como a geometria, gráficos, obras de arte, corpo humano, ou qualquer composição gráfica que carece de explicações além de uma descrição verbal ou por Braille.

É nessa linha que a pesquisa realizou a busca e a compilação de recomendações de autores sobre o planejamento e tradução de uma imagem visual em uma imagem tátil, com o objetivo de trazer à tona a atenção presente na da tradução visual para o tátil de forma compreensível aos cegos.

Especificamente acerca de recomendações para a tradução de imagens táteis (não considerando a impressão 3D), foram levantadas duas pesquisas: a de Loch [2008] e a de BANA [2011].

Loch [2008] é uma pesquisadora da área da cartografia tátil, que propõe recomendações para a criação de mapas táteis, como, por exemplo, a implementação de um leiaute padronizado, e faz a relação entre variáveis gráficas visuais e táteis. As recomendações da autora são dispostas no Quadro
1 a seguir.

\section{RECOMENDAÇÕES PARA CRIAÇÃO DE MAPAS TÁTEIS}

As variáveis táteis são: tamanho, forma, padrão (área/textura) e volume.

Pontos e linhas não devem ultrapassar mais de 3 tamanhos cada.

O ponto pode variar entre $2 \mathrm{~mm}$ e $13 \mathrm{~mm}$

O tamanho mínimo de linha é de 13 mm no comprimento.

A forma pode variar além das formas geométricas básicas (quadrado, círculo, retângulo), utilizando formas mais complexas.

Não recomenda o uso de mais de 2 temas por mapa tátil. Sugere a criação de uma coleção de mapas táteis caso necessário.

Em áreas, utilizar texturas e orientações variadas para o reconhecimento tátil.

Quando uma área for pequena, substituir por Braille.

Recomenda a verificação dos recursos disponíveis para a produção, a portabilidade, e a possibilidade de reprodução dos mapas táteis em locais distintos.

Implementar um leiaute padrão.

Elementos essenciais como escala, título, norte geográfico e legenda são localizados na parte superior do mapa tátil.

Incluir moldura para demarcação do limite da imagem tátil.

Quadro 1 - Recomendações para criação de mapas táteis. Fonte: elaboração das autoras com base em Loch [2008].

Outra fonte de recomendações sobre planejamento e criação de imagens táteis é o documento criado pelo Braille Authority of North America (BANA) e pelo Canadian Braille Authority (CBA), publicado pelo BANA em 2011. O documento consiste em 12 unidades, todavia, o compilado de recomendações do Quadro 2 foi retirado apenas das 3 primeiras: (1.) Critérios para inclusão de imagem tátil; (2.) Princípios de design; e (3.) Planejamento e edição.

RECOMENDAÇÕES PARA CRIAÇÃO DE IMAGENS TÁTEIS

Itens decorativos devem ser excluídos das imagens táteis
Realização:
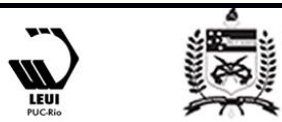
$16^{\circ}$ Ergodesign - Congresso Internacional de Ergonomia e Usabilidade de Interfaces Humano Tecnológica: Produto, Informações Ambientes Construídos e Transporte

$16^{\circ}$ USIHC - Congresso Internacional de Ergonomia e Usabilidade de Interfaces Humano Computador

CINAHPA | 2017 - Congresso Internacional de Ambientes Hipermídia para Aprendizagem.
Simplificar sem perder o sentido da imagem original.

Se o intuito não for apresentação de medidas, é permitido mudanças em leiaute, forma ou posição.

A principal utilização do 3D é para apresentar profundidade e elevação.

Pode acompanhar notas do tradutor, caso necessário.

Manter a consistência de elementos (tamanho, símbolos...) através de um conjunto de imagens.

No planejamento, considerar experiência e idade do usuário final.

Não ultrapassar 5 texturas de área, 5 estilos de linha e 5 símbolos de ponto em uma mesma imagem.

Documentar e listar o conteúdo a ser traduzido, como linhas, áreas, pontos, etc.

Tamanho médio de imagens táteis é de 280 por $290 \mathrm{~mm}$, podendo variar de acordo com a clareza de cada imagem e disponibilidade de material

Área mínima é de $6 \mathrm{~mm}^{2}$. Pequenas áreas são elevadas além das outras áreas para indicar destaque.

Linha mínima de 12,5 mm de comprimento. Linha pontilhada apresenta entre $6 \mathrm{~mm}$ até $10 \mathrm{~mm}$ de tracejado, com pelo menos metade do tamanho de espaço entre eles.

Flechas deverão ser representadas com um triângulo fechado ou ponta de flecha aberta.

Mínimo tamanho de ponto é $6 \mathrm{~mm}$.

Rótulos são apresentados entre 3 e 6 mm de distância do componente, ou acompanhar linha de, pelo menos, $20 \mathrm{~mm}$ até o componente a ser rotulado.

Em caso de rótulo sobrepondo uma textura, manter $3 \mathrm{~mm}$ de margem ao redor do rótulo.

Quando uma imagem estática já contém escala, aumentar a escala proporcionalmente caso seja necessário.

Se necessário, usar 2 vistas de uma mesma imagem estática para representação tátil.

Na simplificação de mapas, elementos como pequenas ilhas, rios, cidades menores etc. poderão ser excluídas na imagem tátil, desde que não comprometam o significado.

Bordas e molduras da imagem estática são eliminadas a não ser que seja uma borda de referência.

Informações secundárias podem ser incluídas como pequenos textos adjacentes.

Áreas similares ou áreas muito pequenas e próximas podem ser agrupadas em apenas uma área.

Imagens estáticas muito complexas devem ser divididas em várias imagens táteis e, nesse caso, deve ser criada uma imagem simplificada do todo para referência. Exemplo de divisão em um mapa é separar elementos como: cidades, recursos minerais, rios e lagos, etc.

Quadro 2 - Recomendações para criação de imagens táteis. Fonte: elaboração das autoras com base em

BANA [2011].

Entre Loch [2008] e o BANA [2011], é possível perceber similaridades e divergências nas recomendações. Entretanto, mesmo nas divergências, a linha de pensamento é similar como obter um tamanho mínimo e máximo para variáveis ponto e linha, por exemplo.

Essas recomendações, mesmo não contemplando a utilização da impressão 3D, são importantes para a discussão, pois independem do meio produtivo e formam a base para a criação de qualquer imagem tátil. Assim, essas recomendações gerais são complementares às recomendações encontradas sobre a criação de imagens táteis impressas em 3D.

\section{Apresentação de imagens táteis através da impressão 3D}

A impressão 3D é uma tecnologia emergente que, aliada com a acessibilidade, permite a expansão dos meios produtivos de imagens táteis para pessoas cegas. Neste quesito, Gual, Puyuelo e Lloveras [2014] defendem o uso das impressoras $3 \mathrm{D}$ como meio produtivo de imagens táteis tendo como principal argumento a possibilidade de imprimir elementos em três dimensões, enquanto as produções mais comuns - termoformagem e impressão em relevo - possuem limitações de volume. Na impressão 3D, então, elementos bidimensionais e tridimensionais podem ser combinados de acordo com a necessidade ou preferência dos usuários.

Alguns autores demonstram a utilização dessa tecnologia na produção das imagens táteis: Voigt e Martens [2006], Celani e Milan [2007], Gual-Ortí, Puyuelo-Cazorla e Lloveras-Macia [2015], Araujo e Santos [2015], Urbas, Pivar e Elesini [2016], e
Realização:

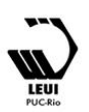




\section{$16^{\circ}$ \\ ERGODESIGN USIHC CINAHPA}

Ramsamy-Iranah et al. [2016]; gerando observações ou recomendações para a sua criação.

Voigt e Martens [2006] desenvolveram um modelo tátil de representação arquitetônica e consideram que o processo de impressão em si é uma das etapas que requer mais atenção, pois deve considerar todaos as limitações da máquina de antemão, como o tamanho máximo de uma impressão, por exemplo.

Já Celani e Milan [2007] desenvolveram mapas táteis para mobilidade na biblioteca central da Universidade Estadual de Campinas (UNICAMP) $\mathrm{e}$, durante os testes de usabilidade, perceberam a necessidade da criação de uma unidade entre os mapas, mantendo, por exemplo, o mesmo leiaute e a mesma escala. Consideram também importante conhecer os usuários, suas experiências prévias e o tipo de cegueira - congênita ou adquirida -, e levar essas informações em consideração na hora da produção de uma imagem tátil.

Ainda sobre mapas táteis, Gual-Ortí, PuyueloCazorla e Lloveras-Macia [2015] realizaram testes comparativos entre um mapa tátil impresso em relevo e um mapa tátil impresso em 3D com elementos bidimensionais e tridimensionais. Como resultado, concluíram que o uso de elementos 3D em mapas táteis reduz o tempo de localização e identificação do símbolo tátil, diminuindo também a quantidade de erros na leitura.

Enquanto isso, Araujo e Santos [2015] realizaram impressões 3D de fotografias para uma exposição de arte e, durante as reflexões de resultados, destacaram a importância de capturar a essência de cada imagem, de maneira simplificada, ao contrário de tentar incluir todos os elementos compositivos da fotografia. Também notaram que o material impresso - gesso - necessitava de pósprocessamento para suavização ao toque.

A necessidade de pós-processamento também foi uma conclusão que Urbas, Pivar e Elesini [2016] destacaram. Criaram mapas táteis para mobilidade em um museu e, utilizando uma impressora 3D com um material plástico, também necessitaram de pós-processamento para suavização da imagem $16^{\circ}$ Ergodesign - Congresso Internacional de Ergonomia e Usabilidade de Interfaces Humano Tecnológica: Produto, Informações Ambientes Construídos e Transporte

$16^{\circ}$ USIHC - Congresso Internacional de Ergonomia e Usabilidade de Interfaces Humano Computador

CINAHPA | 2017 - Congresso Internacional de Ambientes Hipermídia para Aprendizagem.

tátil. Já Ramsamy-Iranah et al. [2016] criaram e compararam 14 símbolos táteis produzidos em 3 materiais diferentes: papel, bordado sobre tecido e impressão 3D. Vale destacar que os impressos 3D obtiveram um reconhecimento mais rápido que os outros materiais. Para o processo de criação dos símbolos, os autores pesquisaram recomendações da literatura sobre símbolos táteis, destacados a seguir.

- Usar formas identificáveis e familiares;

- Usar formas simples;

- Considerar usar tanto contornos quanto formas sólidas;

- Fazer com que os elementos de cada símbolo sejam reconhecíveis;

- Criar cada símbolo diferente e reconhecível, mas manter uma lógica entre eles;

- Fazer símbolos em tamanho adequado (10x10mm);

- Evitar sobreuso de texturas;

- Usar diferentes orientações de forma para um grupo de símbolos;

- Em formas tridimensionais, obter elevação suficiente a partir da base.

Alternativamente, Jovanović, Anđelković e Krstić [2014] se abstiveram apenas na teoria, mas também coletaram recomendações na literatura sobre modelagem e produção de imagens e mapas táteis. As recomendações são apresentadas a seguir:

- A superfície não deve ser muito áspera nem muito lisa;

- O modelo deve conter abstrações de forma e simplificações, para evitar sobrecarga de informações; 
- Recomendável o uso de texturas;

- Caso seja um conjunto de imagens ou mapas, manter a mesma escala;

- Utilizar além de formas geométricas básicas para os elementos;

- Caso o grupo de imagens táteis representem partes de um todo, criar uma imagem tátil em escala menor para representação do todo.

Diante de todas as informações coletadas, é possível perceber algumas iniciativas de incluir a impressão 3D como meio de produção de imagens táteis, resultando em outras recomendações além das vistas anteriormente.

\subsection{Síntese das recomendações}

Com base nas recomendações encontradas na literatura, elaborou-se um quadro de síntese com as recomendações trazidas pelos diversos autores analisados acerca da tradução de imagens táteis utilizando a impressão 3D [Quadro 5].

\begin{tabular}{ll}
\hline RECOMENDAÇÕES & FONTE \\
\hline $\begin{array}{l}\text { Simplificar elementos para } \\
\text { compreensão tátil, porém manter } \\
\text { detalhes essenciais. }\end{array}$ & $\begin{array}{l}\text { Celani; Milan [2007], } \\
\text { Jovanović; Anđelković; Krstić } \\
\text { [2014], Araujo; Santos [2015]; } \\
\text { Ramsamy-Iranah et al [2016] }\end{array}$ \\
$\begin{array}{l}\text { Evitar uso apenas de formas } \\
\text { geométricas básicas }\end{array}$ & $\begin{array}{l}\text { Jovanović; Anđelković; Krstić } \\
\text { [2014] }\end{array}$ \\
$\begin{array}{l}\text { Definir leiaute para o conjunto } \\
\text { de imagens táteis }\end{array}$ & Celani; Milan [2007] \\
$\begin{array}{l}\text { Levar em consideração } \\
\text { limitações técnicas da } \\
\text { impressora 3D }\end{array}$ & Voigt; Martens [2006] \\
$\begin{array}{l}\text { Utilizar pós-processamento para } \\
\text { que a impressão não fique áspera } \\
\text { ou muito lisa }\end{array}$ & $\begin{array}{l}\text { Jovanović; Anđelković; Krstić } \\
\text { [2014], Urbas; Pivar; Elesini } \\
\text { [2016] }\end{array}$ \\
$\begin{array}{l}\text { Combinar elementos de ponto, } \\
\text { linha e textura com informações } \\
\text { tridimensionais (volume) }\end{array}$ & $\begin{array}{l}\text { Jovanović; Anđelković; Krstić } \\
\text { [2014], Gual-Ortí; Puyuelo- } \\
\text { Cazorla; Lloveras-Macia [2015]; } \\
\text { Ramsamy-Iranah et al. [2016] }\end{array}$ \\
& \\
&
\end{tabular}

$16^{\circ}$ Ergodesign - Congresso Internacional de Ergonomia e Usabilidade de Interfaces Humano Tecnológica: Produto, Informações Ambientes Construídos e Transporte

$16^{\circ}$ USIHC - Congresso Internacional de Ergonomia e Usabilidade de Interfaces Humano Computador

CINAHPA | 2017 - Congresso Internacional de Ambientes Hipermídia para Aprendizagem.
Manter a mesma escala para o conjunto de imagens táteis

Criar uma imagem tátil que faça a relação entre o conjunto de outras imagens

Utilizar formas identificáveis e familiares para símbolos, cada símbolo diferente e de fácil identificação

Símbolos com tamanho mínimo de $10 \times 10 \mathrm{~mm}$

Evitar o exagero de texturas

Utilizar diferentes orientações de forma para o grupo de símbolos

Em formas tridimensionais, obter elevação suficiente a partir da base

Levar em consideração o usuário Celani; Milan [2007] - tipo de cegueira, experiências prévias

Celani; Milan [2007]; Jovanović; Anđelković; Krstić [2014]

Jovanović; Anđelković; Krstić [2014]

Ramsamy-Iranah et al. [2016]

Ramsamy-Iranah et al. [2016]

Ramsamy-Iranah et al. [2016]

Ramsamy-Iranah et al. [2016]

Ramsamy-Iranah et al. [2016]

Quadro 5 - Recomendações indicadas na literatura par criação de imagens táteis em 3D. Fonte: as autoras.

Dentre todas as recomendações encontradas, foi possível perceber uma linha de pensamento similar entre os autores, além de semelhanças dentre as recomendações coletadas de Loch [2008] e BANA [2011].

As semelhanças podem ser encontradas na necessidade de simplificação de elementos, de definição de um padrão de leiaute, de manter a mesma escala para imagens táteis, de evitar o exagero de texturas, ou mesmo de levar em consideração as experiências prévias do usuário cego, entre outros. Levando-se em consideração a impressão 3D, as recomendações complementam as anteriores através da atenção para o pósprocessamento e as limitações técnicas da impressora, e também da combinação de elementos de ponto, linha, texturas e objetos volumétricos em três dimensões.

Enquanto isso, as diferenças entre Loch [2008] e BANA [2011] são encontradas no que tange tamanhos mínimos e máximos de elementos como ponto e linha, em manter ou descartar molduras e 


\section{$16^{\circ}$ \\ ERGODESIGN USIHC CINAHPA}

$16^{\circ}$ Ergodesign - Congresso Internacional de Ergonomia e Usabilidade de Interfaces Humano Tecnológica: Produto, Informações Ambientes Construídos e Transporte

$16^{\circ}$ USIHC - Congresso Internacional de Ergonomia e Usabilidade de Interfaces Humano Computador

CINAHPA | 2017 - Congresso Internacional de Ambientes Hipermídia para Aprendizagem. na localização de legendas. Em uma sobreposição de recomendações, seria necessário encontrar um ponto intermediário entre essas divergências.

Mesmo com as diferenças, o pensamento similar de buscar o que é útil e compreensível ao usuário cego foi percebido. Sendo assim, há uma unidade de recomendações formada pelo conjunto de Loch [2008], BANA [2011] e dos autores citados sobre imagens táteis impressas em 3D.

\section{Considerações finais}

O presente artigo realizou um breve contexto sobre pessoas cegas e a percepção tátil, e destacou a importância de transformar imagens visuais em táteis para esse público. Também, salientou a impressão 3D como meio facilitador da produção destas imagens.

Além disso, buscou-se reunir recomendações encontradas na literatura sobre tradução, planejamento e criação de imagens táteis, em especial, através da impressão 3D. Acerca de tais recomendações, pode-se identificar pontos convergentes e divergentes dentre as recomendações analisadas.

Há ainda muito a se pesquisar sobre o assunto, não sendo objetivo desta pesquisa esgotar ou encerrar a procura por recomendações e melhores práticas na criação de imagens táteis. Pesquisas futuras incluem a sobreposição destas recomendações, a proposição de um modelo efetivo para a tradução de imagens visuais em imagens táteis e testes de compreensão com potenciais usuários com imagens táteis criadas a partir desse modelo.

\section{BIBLIOGRAFIA}

AMIRALIAN, M. L. T. M. Compreendendo o cego: uma visão psicanalítica da cegueira por meio de desenhos-estórias. São Paulo: Casa do Psicólogo, 1997. 321 p.

AMIRALIAN, M. L. T. M. Deficiência visual: perspectivas na contemporaneidade. São Paulo:
Vetor, 2009. $270 \mathrm{p}$.

ARAUJO, M. D. X; SANTOS, D. M. Fotografia Tátil: desenvolvimento de modelos táteis a partir de fotografias com a utilização de impressora $3 \mathrm{~d}$. Revista Brasileira de Design da Informação Infodesign, São Paulo, v. 12, n. 1, p. 62-76, 2015.

\section{BANA - THE BRAILLE AUTHORITY OF NORTH AMERICA. Guidelines and standards for tactile graphics. Disponível em: \\ <http://www.brailleauthority.org/tg/index.html >. Acesso em: 16 fev. 2017.}

BRASIL. Subsecretaria Nacional de Promoção dos Direitos da Pessoa com Deficiência. Comitê de Ajudas Técnicas. Tecnologia assistiva. Brasília: CORDE, 2009. 138p.

CELANI, G.; MILAN, L. F. Tactile scale models: three-dimensional info-graphics for space orientation of the blind and visually impaired. In: INTERNATIONAL CONFERENCE ON ADVANCED RESEARCH IN VIRTUAL AND RAPID PROTOTYPING, $3^{\circ}$, 2007, Leiria, Portugal. Anais do $3^{\circ}$ International Conference On Advances Research in Virtual and Rapid Prototyping. Leiria, 2007, p.801-806.

CHICCA JUNIOR, N.; CASTILLO, L.; COUTINHO, S. 2015. A impressão 3D contribuindo em projetos de design da informação. In: CONGRESSO INTERNACIONAL DE DESIGN DA INFORMAÇÃO, $7^{\circ}, 2015$, Brasília, DF. Anais do $7^{\circ}$ Congresso Internacional de Design da Informação. Brasília: Blucher, 2015, p. 1355-1360.

DUARTE, M. L. B. Desenho infantil e seu ensino a crianças cegas: razões e métodos. Curitiba: Insight, 2011. 204 p.

FLORES, Â.; SOMBRIO, G.; TAKIMOTO, T.; ULBRICHT, V. A aprendizagem de geometria por alunos cegos. In: CONAHPA - CONGRESSO NACIONAL DE AMBIENTES HIPERMÍDIA PARA APRENDIZAGEM, $7^{\circ}, 2015$, São Luís, MA. Anais do $7^{\circ}$ Conahpa. São Luís, 2015.

FUNDAÇÃO DORINA NOWILL. O que é
Realização:

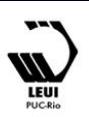




\section{$16^{\circ}$ \\ ERGODESIGN USIHC CINAHPA}

deficiência? 2017. Disponível em:

https://www.fundacaodorina.org.br/a-

fundacao/deficiencia-visual/o-que-e-deficiencia/.

Acesso em: 28 Fev. 17.

GRUENWALD, L. Impressão 3d: lendo imagens através do tato. Um recurso a mais para estudantes com deficiência visual. Revista nacional de reabilitação - reação, n. 98, Maio/ Junho, 2014.

GUAL, J.; PUYUELO, M.; LLOVERAS, J. Threedimensional tactile symbols produced by 3D Printing: Improving the process of memorizing a tactile map key. British Journal of Visual Impairment, v. 32, n. 3, p. 263-278, 2014.

GUAL-ORTÍ, J.; PUYUELO-CAZORLA, M.; LLOVERAS-MACIA, J. Improving tactile map usability through $3 \mathrm{D}$ printing techniques: an experiment with new tactile symbols. The Cartographic Journal, v. 52, n.1, p. 51-57, 2015.

IBGE - INSTITUTO BRASILEIRO DE GEOGRAFIA E ESTATÍSTICA. Censo demográfico 2010: características gerais da população, religião e pessoas com deficiência. 2010. Disponível em:

$<$ http://biblioteca.ibge.gov.br/visualizacao/periodic os/94/cd_2010_religiao_deficiencia.pdf $>$. Acesso em: 23 Ago. 2016.

JOVANOVIC, N.; ANDELKOVIC, B.; KRSTIC, $\mathrm{H}$. The role of 3D printing in the making of models for tactile perception of architectural objects. In: MONJEOMETRIJA - INTERNATIONAL SCIENTIFIC CONFERENCE ON GEOMETRY AND GRAPHICS, $4^{\circ}, 2014$, Vlasina, Sérvia. Anais do $4^{\mathbf{0}}$ moNGeometrija. Vlasina, 2014.

KASTRUP, V. A invenção na ponta dos dedos: a reversão da atenção em pessoas com deficiência visual. Psicologia em Revista, Belo Horizonte, v. 13, n. 1, p. 69-90, 2007.

KURZE, Martin. TDraw: a computer-based tactile drawing tool for blind people. In: ANNUAL ACM CONFERENCE ON ASSISTIVE

TECHNOLOGIES, $2^{\circ}$, 1996, New York, NY, EUA. Anais do $2^{\circ} \mathrm{ACM}$ Conference on Assistive Technologies. New York: ACM, 1996, p.131-138. $16^{\circ}$ Ergodesign - Congresso Internacional de Ergonomia e Usabilidade de Interfaces Humano Tecnológica: Produto, Informações Ambientes Construídos e Transporte

$16^{\circ}$ USIHC - Congresso Internacional de Ergonomia e Usabilidade de Interfaces Humano Computador

CINAHPA | 2017 - Congresso Internacional de Ambientes Hipermídia para Aprendizagem.

LOCH, R. E. N. Cartografia tátil: mapas para deficientes visuais. Portal da Cartografia, Londrina, v.1, n.1, p. 35-58, 2008.

MACEDO, C. M. S. Diretrizes para criação de objetos de aprendizagem acessíveis. 2010, 271p. Tese (Doutorado em Engenharia e Gestão do Conhecimento). Universidade Federal de Santa Catarina, Florianópolis, 2010.

ORTÍ, J.; PITARCH, M. J. M.; RUBIO, J. T. G.; MOYA, J. Á. M.; CAZORLA, M. P. Expresión Gráfica Tangible. In: CONGRESO

INTERNACIONAL EXPRESIÓN GRÁFICA APLICADA A LA EDIFICACIÓN, 12², 2014, Madri, Espanha. Anais do XII Congreso Internacional Expresión Gráfica Aplicada A La Edificación. Madri, 2014.

QUEVEDO, S. R. P.; ULBRICHT, V. R. Como os cegos aprendem. In: ULBRICHT, V. R.; VANZIN, T.; VILLAROUCO, V. (Org.). Ambiente virtual de aprendizagem inclusivo. Florianópolis: Pandion, 2011. $352 \mathrm{p}$.

RAMSAMY-IRANAH, Sabrina; MAGUIRE, Martin; GARDNER, James; ROSUNEE, Satyadev; KISTAMAH, Naraindra. A comparison of three materials used for tactile symbols to communicate colour to children and young people with visual impairments. British Journal of Visual Impairment, v. 34, n.1, p. 54-71, 2016.

SACKS, O. O olhar da mente. São Paulo: Companhia das Letras, 2010.

SOBRAL, J. E. C.; CAVALCANTI, A. L. M. S.; EVERLING, M. T. 'Ver com as mãos': a tecnologia 3D como recurso educativo para pessoas cegas. 2015. In: ERGODESIGN CONGRESSO INTERNACIONAL DE ERGONOMIA E USABILIDADE DE INTERFACES HUMANO-TECNOLOGIA, 15', 2015, Recife, PE. Anais do $\mathbf{1 5}^{\circ}$ Ergodesign. Recife, 2015.

UN - UNITED NATIONS. The invisibility of disability. Disponível em: $<$ http://www.un.org/disabilities/documents/sdgs/inf ographic_statistics_2016.pdf>. Acesso em: $17 \mathrm{fev}$.
Realização:

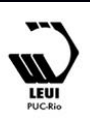




\section{$16^{\circ}$ \\ ERGODESIGN USIHC CINAHPA}

$16^{\circ}$ Ergodesign - Congresso Internacional de Ergonomia e Usabilidade de Interfaces Humano Tecnológica: Produto, Informações Ambientes Construídos e Transporte

$16^{\circ}$ USIHC - Congresso Internacional de Ergonomia e Usabilidade de Interfaces Humano Computador

CINAHPA | 2017 - Congresso Internacional de Ambientes Hipermídia para Aprendizagem.

2017.

URBAS, R.; PIVAR, M.; ELESINI, U. S.

Development of tactile floor plan for the blind and the visually impaired by 3D printing technique.

Journal of Graphic Engineering and Design, v. 7, n.1, p. 19-26, 2016.

VALENTE, D. Os diferentes dispositivos de fabricação de imagens e ilustrações táteis e as possibilidades de produção de sentido no contexto perceptivo dos cegos. Revista Educação, Artes e Inclusão, Florianópolis, v.2, n. 1, p. 59-82, 2009.

VOIGT, A.; MARTENS, B. Development of 3D tactile models for the partially sighted to facilitate spatial orientation. In: eCAADe, $24^{\circ}, 2006$, Volos, Grécia. Anais do $24^{\mathbf{0}}$ eCAADe. Volos, Grécia, 2006, p. 366-370. 